Ян А. Сухих, Дмитрий И. Правиков, Алексей А. Кузичкин

РАЗРАБОТКА ЗАЩИЩЕННЫХ АРХИТЕКТУР АВТОМАТИЗИРОВАННЫХ СИСТЕМ

УПРАВЛЕНИЯ ТЕХНОЛОГИЧЕСКИМИ ПРОЦЕССАМИ

\author{
Ян А. Сухих ${ }^{1}$, Дмитрий И. Правиков ${ }^{2}$, Алексей А. Кузичкин ${ }^{3}$ \\ ${ }^{1}$ «Ростелеком-Солар», \\ Никитский пер. 7, стр. 1, Москва, 125009, Российская Федерация \\ ${ }^{2}$ РГУ нефти и газа (НИУ) имени И.М. Губкина, \\ Ленинский пр-кт, 65, корп. 1, Москва, 119991, Российская Федерация \\ «Шнейдер Электрик Центр Инновачий», \\ ул. Университетская, 7, Иннополис, 420500, Российская Федерация \\ ${ }^{1}$ e-mail: y.sukhikh@rt-solar.ru, https://orcid.org/0000-0002-0273-023X \\ 2e-mail:dip@gubkin.pro,https://orcid.org/0000-0001-5217-4537 \\ 3e-mail: ansabanyr13@yandex.ru, https://orcid.org/0000-0001-5315-4466

\section{РАЗРАБОТКА ЗАЩИЩЕННЫХ АРХИТЕКТУР АВТОМАТИЗИРОВАННЫХ СИСТЕМ УПРАВЛЕНИЯ ТЕХНОЛОГИЧЕСКИМИ ПРОЦЕССАМИ DOI: http://dx.doi.org /10.26583/bit.2020.2.08}

Аннотащия. В настоящее время основным документом, описывающим требования к созданию систем информационной безопасности АСУ ТП промышленных предприятий, является стандарт МЭК 62443. Вместе с тем, опыт его применения выявил ряд аспектов, не описанных или недостаточно подробно описанных в стандарте, но требующих дополнительной детализации для правильного использования, в частности в статье выделяется этап разработки архитектуры защищенной АСУ ТП. В статье рассмотрена обобщенная методика разработки архитектуры, основанная на концепте «зон и связей», детально рассмотрены этапы инвентаризации, определения зон и связей. В статье отмечается, что ключевым элементом, определяющим устойчивость общей системы защиты, является системы противоаварийной защиты, поэтому их интеграции с системами управления уделено особое внимание, в частности рассмотрено несколько способов интеграции, отмечены их преимущества и недостатки. Приведен ряд практических рекомендаций по реализации предложенной методики.

Ключевые слова: АСУ ТП промышленных предприятий, информационная безопасность, кибербезопасность, архитектура системы защиты АСУ ТП, методика проектирования.

Для иитирования. СУХИХ, Ян А.; ПРАВИКОВ, Дмитрий И.; КУЗИЧКИН, Алексей А. РАЗРАБОТКА ЗАЩИЩЕННЫХ АРХИТЕКТУР АВТОМАТИЗИРОВАННЫХ СИСТЕМ УПРАВЛЕНИЯ ТЕХНОЛОГИЧЕСКИМ ПРОЦЕССАМИ. Безопасность информаиионных технологий, [S.l.], v. 27, n. 2, p. 97-117, 2020. ISSN 2074-7136. Доступно на: <https://bit.mephi.ru/index.php/bit/article/view/1274>. Дата docmyna: 27 may 2020. doi:http://dx.doi.org/10.26583/bit.2020.2.08.

\author{
Yan A. Sukhikh ${ }^{1}$, Dmitry I. Pravikov², Alexey A. Kuzichkin ${ }^{3}$ \\ 1 "Rostelecom-Solar", \\ Nikitsky Lane 7,str. 1, Moscow, 125009, Russia \\ ${ }^{2}$ National University of Oil and Gas "Gubkin Universit", \\ Leninsky av. 65, bd. 1, Moscow, 119991, Russia \\ 3 "Schneider Electric Innovation Center", \\ Universitetskaya Str., 7, Innopolis, 420500, Russia \\ ${ }^{1}$ e-mail: y.sukhikh@rt-solar.ru, https://orcid.org/0000-0002-0273-023X \\ 2e-mail:dip@gubkin.pro,https://orcid.org/0000-0001-5217-4537 \\ 3e-mail: ansabanyr13@yandex.ru, https://orcid.org/0000-0001-5315-4466
}

\title{
Development of secure architectures for process control systems
}

DOI: http://dx.doi.org /10.26583/bit.2020.2.08

Abstract. The IEC 62443 standard is the main document describing the requirements for building secure industrial control systems. However, a number of aspects are not properly described or not sufficiently detailed in the standard, and require additional detail for a proper implementation. In particular, the paper highlights main stages of secure industrial control systems architecture development. Secure architecture 
development approach is based on the "zones and conduits" concept and includes detailed description of inventory stage and zones and conduits determination. Considering that emergency shutdown systems (safety systems) are the key element preventing assets from major accidents, special attention is paid to its integration with control systems. Several integration methods are described with its advantages and disadvantages noted. Recommendations for the practical implementation of the proposed methodology are given.

Keywords: ICS/SCADA, information security, cybersecurity, secure ICS/SCADA architecture, design methodology.

For citation: SUKHIKH, Yan A.; PRAVIKOV, Dmitry I.; KUZICHKIN, Alexey A. Development of secure architectures for process control systems. IT Security (Russia), [S.l.], v. 27, n. 2, p. 97-117, 2020. ISSN 2074-7136. Available at: <https://bit.mephi.ru/index.php/bit/article/view/1274>. Date accessed: 27 may 2020. doi:http://dx.doi.org/10.26583/bit.2020.2.08.

\section{Введение}

Данная работа посвящена кибербезопасности автоматизированных систем управления технологическим процессом (АСУ ТП). Вопрос защиты промышленных систем управления от киберугроз стал особенно актуальным с началом четвертой промышленной революции (Industry 4.0), когда с целью оптимизации и повышения эффективности производств, промышленные системы управления начали массово подключать к корпоративным информационным системам и глобальной сети Internet.

При построении защищённых промышленных систем управления необходимо учитывать два главных фактора: говорить о кибербезопасности необходимо в контексте комплексной безопасности промышленного предприятия и необходимо выдерживать баланс между безопасностью и удобством использования системы / ее стоимостью. В коммерческом секторе задачи бизнеса всегда имеют высочайший приоритет и важно, чтобы кибербезопасность не стала блокирующим фактором развития бизнеса, она должна стать помощником - помогать бизнесу безопасно внедрять современные цифровые технологии.

Активное внедрение АСУ для управления технологическими процессами в различных отраслях промышленности не только повысило эффективность производства [1], но и породило ряд проблем, в первую очередь связанных с обеспечением информационной безопасности [2]. Указанные проблемы отражены не только в научной литературе, но и в отчетах ведущих компаний, специализирующихся в области информационной безопасности ${ }^{1}$. Показателем значимости угроз кибербезопасности для промышленности является то, что согласно исследованию аналитиков, подготовивших отчет Международного Экономического Форума “The Global Risk Report 2019” by World Economic Forum ${ }^{2}$, они вошли в ТОР-5 наиболее ожидаемых рисков, с которыми компании могут столкнуться.

Для снижения уровня указанных рисков в промышленно развитых странах активно развиваются как средства обеспечения информационной безопасности АСУ ТП, так и организационно-технические решения. При этом вопросы построения системы защиты и применения указанных средств и решений регламентируются целым рядом нормативных актов, в том числе отраженные в ряде стандартов. Краткий обзор рассматриваемых документов приведен в [3].

\footnotetext{
${ }^{1}$ Threat landscape for industrial automation systems, H1 2019. URL: https://ics-cert.kaspersky.com/reports/ 2019/09/30/threat-landscape-for-industrial-automation-systems-h1-2019/ (дата обращения: 01.04.2020).

${ }^{2}$ The Global Risks Report 2019. URL: https://www.weforum.org/reports/the-global-risks-report-2019 (дата обращения: 01.04.2020).
} 
В Российской Федерации указанную систему образует Федеральный закон от 26.07.2017 №187-Ф3 «О безопасности критической информационной инфраструктуры Российской Федерации» и целый ряд подзаконных нормативных актов, среди которых необходимо выделить непосредственно ориентированный на реализацию системы защиты информации критической информационной инфраструктуры Приказ ФСТЭК России от 25.12.2017 № 239 «Об утверждении требований по обеспечению безопасности значимых объектов критической информационной инфраструктуры Российской Федерации», а также Приказ ФСТЭК России от 14.03.2014 №31 «Об утверждении требований к обеспечению защиты информации в автоматизированных системах управления производственными и технологическими процессами на критически важных объектах, потенциально опасных объектах, а также объектах, представляющих повышенную опасность для жизни и здоровья людей и для окружающей природной среды».

За рубежом, в первую очередь в США и Западной Европе, в качестве общего рамочного документа используется документ американской организации NIST «Framework for Improving Critical Infrastructure Cybersecurity» [4], а также МЭК 62443 [5] (частично гармонизированный в Российской Федерации - ГОСТ Р 56205-2014) и ISA 62443 - серия стандартов, разработанных двумя группами: ISA99 и IEC TC65/WG10.

Проведенный экспертный сравнительный анализ двух систем нормативных актов показывает их подобие друг другу при реализации технических деталей обеспечения информационной безопасности промышленных предприятий ${ }^{3}$. При этом разница заключается в реализации общей концепции защиты на уровне предприятия, национальных отраслей промышленности или в целом национального производства. По мнению отдельных экспертов, международные стандарты в области кибербезопасности, а также стандарты некоторых западных стран опережают по уровню проработки стандарты, действующие в Российской Федерации. Исходя из того, что стандарт МЭК 62443 принят раньше, в отношении практики его применения накоплен более значительный опыт, позволяющий учесть не только положительные стороны, но и выявить аспекты, вызвавшие трудности при его реализации.

Как показывает практика, несмотря на развитую нормативную базу, существующие средства и методы обеспечения информационной безопасности промышленных предприятий, в ряде случаев не обеспечивают надлежащего уровня защищенности. Недостаток знаний, сложность и/или недостаточный уровень детализации стандартов приводит к тому, что организации не могут создать эффективную систему защиты информации. Как следствие, возникает двуединая задача: а) определить, почему в результате применения действующих стандартов (в частности стандарта МЭК 62443) в ряде случаев не обеспечивается приемлемый уровень информационной безопасности промышленных предприятий; б) предложить пути повышения уровня фактической защищенности современных предприятий.

Для решения указанной задачи предлагается:

- провести анализ наиболее известных стандартов в области обеспечения информационной безопасности АСУ ТП и практики их применения;

- сформировать методики по созданию защищенных систем управления;

- предложить решения по повышению уровня защищенности систем, относящихся к критической информационной инфраструктуре.

\footnotetext{
${ }^{3}$ https://www.ptsecurity.com/upload/corporate/ru-ru/analytics/FSTEC-N31-NERK-NIST-ISA-IEC-rus.pdf
} 
Ян А. Сухих, Дмитрий И. Правиков, Алексей А. Кузичкин

РАЗРАБОТКА ЗАЩИЩЕННЫХ АРХИТЕКТУР АВТОМАТИЗИРОВАННЫХ СИСТЕМ

УПРАВЛЕНИЯ ТЕХНОЛОГИЧЕСКИМИ ПРОЦЕССАМИ

\section{1. Общие проблемы обеспечения кибербезопасности АСУ ТП}

В соответствии с экспертным мнением, выраженном, в частности, на конференции Indusrial Cybersecurity ${ }^{4}$, кибербезопасность систем промышленной автоматизации «в чистом виде» практически не интересует организаторов бизнеса. Более того, как показал опыт расследования киберинцидентов на промышленных предприятиях в первый момент времени очень трудно отличить изменение поведения управляемого оборудования, произошедшего в результате кибератаки, от сбоя, вызванного износом, отказом оборудования или неквалифицированным действием персонала. В результате рассматривают информационную безопасность в совокупности с функциональной безопасностью промышленных систем и операционными рисками, связанными с работой и обслуживанием этих систем и систем управления. Отсюда появилось понятие комплексной безопасности промышленных систем, включающей в себя функциональную безопасность, операционную (промышленную - в терминах российской нормативной базы) безопасность и кибербезопасность [6]. При этом функциональная и операционная безопасность обеспечиваются своими системами контроля, которые тоже должны отвечать требованиям кибербезопасности.

Как следствие, для обеспечения такой комплексной безопасности привлекаются различные группы специалистов, которым приходится преодолевать ряд субъективных проблем, описанных, в частности, в [7]:

1. Традиционно инженеры АСУ ТП не обладают достаточным количеством знаний в области кибербезопасности, а инженеры информационной безопасности (ИБ) или информационных технологий (ИТ) не понимают потребностей и особенностей АСУ ТП. Для создания надежной и безопасной АСУ ТП и/или для должной адаптации стандартов под конкретную систему, персонал должен обладать экспертными знаниями в ИТ, АСУ ТП и кибербезопасности. При этом подходы специалистов АСУ ТП и специалистов ИБ к решению проблем могут иметь противоположную направленность.

В апреле 2020 года был проведён опрос экспертного сообщества с целью определения размеров системы, для которых использование централизованных средств управления информационной безопасностью становится оправданным. $80 \%$ аудитории составляли инженеры и эксперты ИБ, $20 \%$ - инженеры АСУ ТП и руководители среднего звена. Разброс результатов получился существенным, что свидетельствует об отсутствии единого мнения у представителей экспертного сообщества. По результатам опроса хотелось бы выделить следующие тренды, иллюстрирующие отличия в подходах:

- Инженеры АСУ ТП менее склонны к использованию централизованных средств управления ИБ. По всем вопросам они проголосовали, что сервисы либо не нужны вообще, либо нужны для очень больших систем. Эти результаты свидетельствуют о нежелании представителей АСУ ТП добавлять новые сервисы в классические АСУ.

- Инженеры ИБ более склонны к использованию централизованных средств управления ИБ и считают оправданным их использование даже для маленьких систем. Скорее всего, это связано с тем, что использование централизованных средств управления ИБ способно существенно сократить трудозатраты на конфигурирование и управление системой, разбор инцидентов и т.д.

Другие сведения по результатам проведенного опроса представлены в приложении 1.

2. Сложность систем и стандартов. Так, рассматриваемый в статье стандарт МЭК 62443 имеет достаточно сложную структуру, а в содержании стандарта много требований,

\footnotetext{
${ }^{4}$ https://ics.kaspersky.ru/conference-2019/
} 
которые могут трактоваться неоднозначно и не всегда интерпретируются пользователями корректно.

3. Ряд существенных аспектов в нормативных документах ФСТЭК России и рассматриваемых стандартах имеет относительно общий уровень требований. Вместе с тем, как показала практика создания конкретных систем защиты, детализация реализации таких требований может оказать существенное влияние на общий уровень безопасности промышленных систем. В отдельных случаях может сложиться ситуация, когда формальное выполнение требований действующих стандартов не обеспечивает фактической защищенности.

Наиболее существенной проблемой, с которой на наш взгляд столкнулись разработчики систем защиты АСУ ТП промышленных предприятий, является разработка архитектуры защищенной промышленной системы управления. Так, например, в [8] приводится описание архитектуры системы защиты АСУ ТП объекта нефтедобычи, при этом какого-либо обоснования предложенного решения не приведено. Аналогично, в [9] вопросы обоснования архитектуры защиты носят описательный характер. Планирование архитектуры защищенной АСУ ТП, ее основных технологий и решений является первым и наиболее ответственным этапом создания системы. Любые ошибки и недоработки на этом этапе впоследствии могут привести к серьезным недостаткам системы в области кибербезопасности и/или к существенным экономическим потерям на исправление ошибок на уже внедренной системе [10]. При этом качественное выполнение работ на данном этапе поможет не только повысить защищенность информационных систем, но и существенно сократить затраты на внедрение и обслуживание системы защиты информации.

\section{2. Методика разработки архитектуры защищенной АСУ ТП}

В качестве основы для разработки архитектуры выбран концепт «зоны и связи» или «зоны и тракты», описанный в МЭК 62443. Концепт «зоны и связи» описывает как различные системы взаимодействуют друг с другом, как и в какой форме информация передается между системами, каковы различия в требованиях к безопасности в различных зонах. Этот концепт изначально ориентирован на системы АСУ ТП, как следствие его удобно использовать для разработки архитектур систем защиты. Дополнительно использован «Сyber Security for Industrial Automation and Control Systems (IACS) EDITION 2» [11], разработанный комитетом здравоохранения и безопасности Великобритании и ориентированный на практическое использование МЭК 62443.

\section{3. Инвентаризация}

Первым шагом при создании защищенных АСУ ТП должна быть инвентаризация, в рамках которой собирается информация об активах:

- информация о технологических установках и схемы материальных потоков;

- планы расположения оборудования и установок;

- информация об информационных системах и АСУ ТП, поддерживающими работу;

- информация о зависимостях между информационными системами, АСУ ТП и технологическими установками;

- общая информация об информационных системах и АСУ ТП, включая данные о производителе, номера версий общесистемного и прикладного программного обеспечения, год внедрения и другие данные;

- информация о сетях (связях) в соответствии с [12]; 
Ян А. Сухих, Дмитрий И. Правиков, Алексей А. Кузичкин

РАЗРАБОТКА ЗАЩИЩЕННЫХ АРХИТЕКТУР АВТОМАТИЗИРОВАННЫХ СИСТЕМ УПРАВЛЕНИЯ ТЕХНОЛОГИЧЕСКИМИ ПРОЦЕССАМИ

- информация о взаимодействии с сервисами третьих поставщиков, включая провайдеров облачных сервисов;

- информация о имеющихся средствах защиты информации;

- информация о существующих политиках и процедурах, принятых в компании.

Данная информация необходима для корректного разделения системы на зоны и при анализе рисков.

Наши исследования показали, что менее 5\% промышленных компаний в нашей стране имели достаточный уровень осведомлённости о своих производственных подразделениях и процессах до того, как они попали под действие федерального законодательства - Федеральный закон №187-Ф3 «О безопасности критической информационной инфраструктуры Российской Федерации». Закон обязал компании собирать и анализировать все данные, относящиеся к критическим информационным системам, что значительно повысило осведомлённость компаний и позволяет им двигаться дальше.

\section{4. Как определить зоны и связи?}

После того как информация по активам была собрана и проанализирована можно приступать к разделению системы на зоны и связи. Количество зон, то, как активы будут сгруппированы должно определяться индивидуально для каждого конкретного случая на основе следующих факторов:

- тяжесть последствий в результате аварии и/или останова производства/ предоставления услуги;

- размер, функциональное назначение, зависимости от других систем;

- стандарты и требования регуляторов;

- удобство использования и соображения кибербезопасности;

- географическое положение;

- совокупная стоимость системы.

Обычно зоны включают:

- Зона(-ы) систем управления. Эти зоны обычно включают все базовые системы управления технологическими процессами (БСУ ТП, в терминологии МЭК 62443 - basic process control systems). Обычно одна БСУ ТП эквивалентна одной распределенной системе управления (РСУ), или одной функционально законченной системе с архитектурой человеко-машинного интерфейса (ЧМИ) - ЧМИ/SCADA, но такое разделение не является обязательным правилом. В некоторых случаях БСУ ТП могут включать несколько систем.

- Зона(-ы) систем промышленной безопасности. Эти зоны обычно включают системы противоаварийной защиты (ПАЗ) и другие критичные с точки зрения безопасности производства системы.

- Зона(-ы) систем кибербезопасности. В этих зонах обычно располагаются технические и программные средства, обеспечивающие защиту других зон от киберугроз, например, контроллер домена, сетевые системы обнаружения вторжений, сервер сбора и анализа логов и т.д.

- Зона(-ы) систем управления энергоснабжением. Эти зоны включают в себя системы управления и мониторинга энергоснабжением.

- Зона(-ы) систем управления производством. К этим зонам рекомендуется относить системы, работающие на уровне выше, чем SCADA / PCУ, и не имеющие прямого влияния на технологический процесс. Это могут быть системы класcа Historian 
Ян А. Сухих, Дмитрий И. Правиков, Алексей А. Кузичкин

РАЗРАБОТКА ЗАЩИЩЕННЫХ АРХИТЕКТУР АВТОМАТИЗИРОВАННЫХ СИСТЕМ

УПРАВЛЕНИЯ ТЕХНОЛОГИЧЕСКИМИ ПРОЦЕССАМИ

(или центральный (основный), системы оперативного управления производством (MES), аналитические системы, системы усовершенствованного управления технологическими процессами (СУУ ТП / АРС), системы класса Intelligence и другие.

- Демилитаризованная(-ые) зона (ДМЗ). В эти зоны должны быть размещены все сервисы, которые обеспечивают коммуникации между зонами, относящимися к АСУ ТП, и корпоративной сетью или другими «недоверенными» зонами.

- Другие зоны. Сюда могут быть включены все остальные внутренние или внешние зоны (например, комплексные системы управления), или зоны, которыми управляют третьи поставщики (облачные сервисы).

Каждый интерфейс, по которому зоны взаимодействуют между собой, должен быть учтен как «связи», например:

- все коммуникационные интерфейсы между зонами внутри АСУ ТП;

- все коммуникации между внутренними и внешними зонами, а также зонами, обслуживаемыми сторонними поставщиками;

- беспроводные коммуникации;

- переносные (USB устройства, переносные HDD, ноутбуки и др.) и другие не сетевые способы передачи цифровой информации;

- для наиболее ответственных систем дополнительно могут быть учтены способы передачи информации, которые могут использоваться при проведении атак по сторонним каналам: окна, системы видеонаблюдения, кабели питания, сетевые кабели, ЭМИ, микрофоны и т.д.

Как «связи» не должны учитываться стандартные унифицированные электрические сигналы, такие как DI - дискретные входы, DO - дискретные выходы и AI, AO аналоговые входы и выходы.

Пример практической реализации концепции МЭК 62443 «зоны и связи» показан на рис. 1.

Важно отметить, что состав зон может отличать от представленного, в зависимости от корпоративных стандартов, особенностей предприятия и исторически сложившихся практик. В вопросе разделения по зонам нет, и не может быть, жестких правил, а только рекомендации - слишком многое зависит от уникальных особенностей каждого объекта. Например, сервер Historian может располагаться в зоне систем управления или в зоне систем управления производством; системы оперативного управления производством MES часто размещают в зоне управления производством и в корпоративной сети предприятия; системы класса СУУ ТП (АРС) во многих случаях целесообразнее разместить в зоне системы управления, а сервисы обновлений размещать в ДМ3, как, например, сервис обновлений операционных систем и продуктов Microsoft (WSUS), который не работает оффлайн или без подключения с вышестоящими WSUS серверами.

Несмотря на разнообразие возможных вариантов построения архитектур существует свод базовых рекомендаций единых для всех систем:

- Зона систем промышленной безопасности и, в частности, системы ПАЗ - это последний рубеж защиты активов от серьезных аварий и эти системы/зоны должны быть максимально защищены и изолированы в соответствии с концепцией «защита в глубину» [13]. 
Ян А. Сухих, Дмитрий И. Правиков, Алексей А. Кузичкин

РАЗРАБОТКА ЗАЩИЩЕННЫХ АРХИТЕКТУР АВТОМАТИЗИРОВАННЫХ СИСТЕМ УПРАВЛЕНИЯ ТЕХНОЛОГИЧЕСКИМИ ПРОЦЕССАМИ

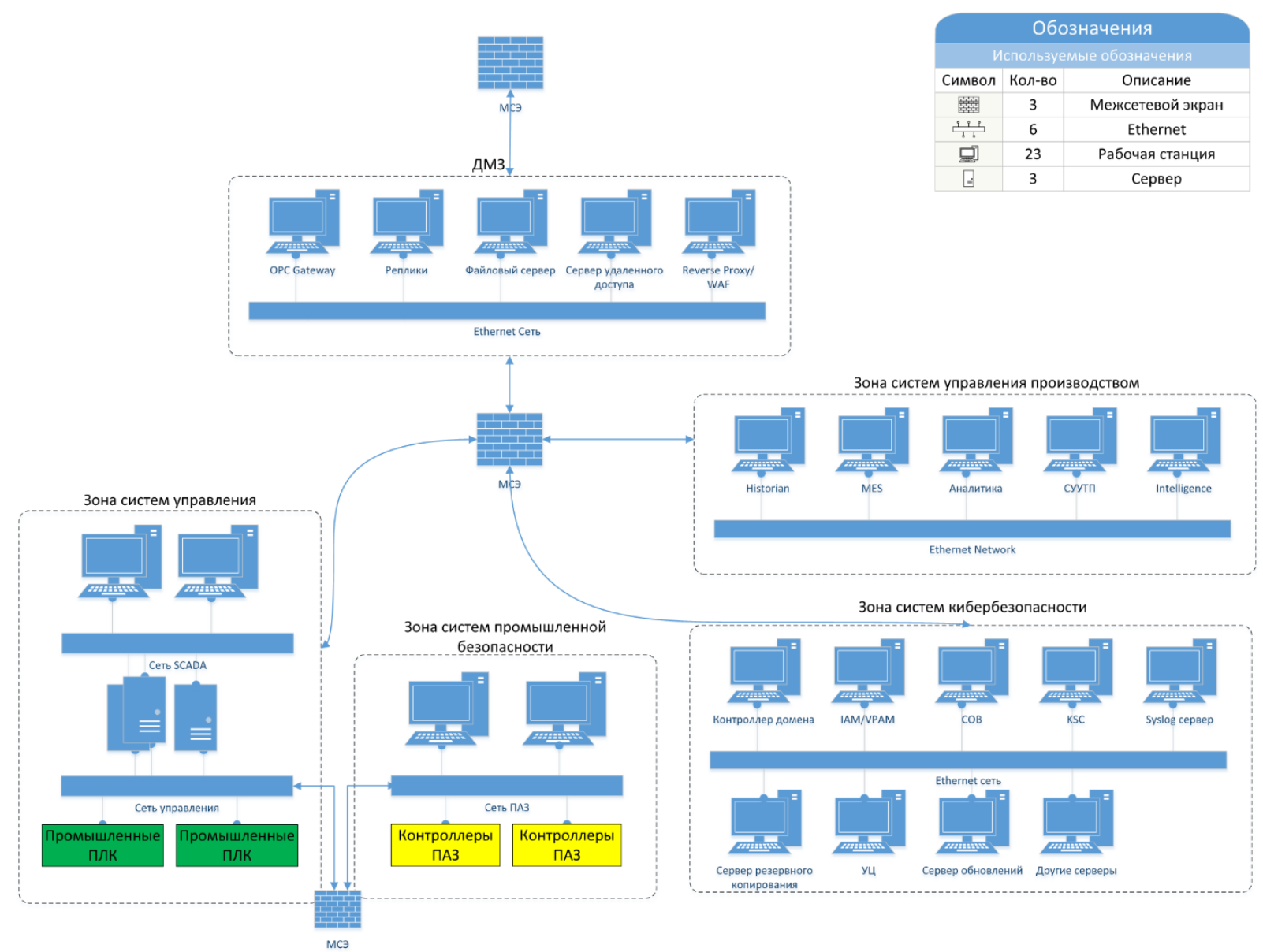

Рис. 1. Пример практической реализаџии кониепџии «зоны и связи» стандарта МЭК 62443

(Fig. 1. Example of practical implementation of the IEC 62443 approach, based on «zones and conduits» concept)

- Все системы, которые непосредственно влияют на технологический процесс, но не являются системами ПАЗ, рекомендуется размещать в зоне систем управления.

- Все сервисы, которые поддерживают работу БСУ ТП, но не влияют непосредственно на технологический процесс желательно размещать в зоне систем управления или на вышестоящих уровнях.

- Все коммуникации между зонами должны быть подробно описаны (протоколы, порты, IP-адреса).

- Правила межсетевого экранирования должны быть разработаны с учетом информационных потоков между зонами. По возможности необходимо указывать конкретные хосты и протоколы в правилах и избегать использования подсетей и правил «любой».

- Все коммуникации между зонами, относящимися к БСУ ТП и корпоративной сетью, должны осуществляться через ДМЗ, сквозные коммуникации настоятельно не рекомендуется использовать.

- Разбиение на зоны должно быть выполнено таким образом, что нарушения связи между зонами не должны приводить к немедленному останову технологического 
процесса. Технологический процесс должен продолжаться (возможно, в режиме ограниченной функциональности) до восстановления связей между зонами.

- Если возможно, рекомендуется избегать использования зашифрованного трафика между ДМЗ и внутренними доверенными зонами (HTTPS и т. п.). Минимальное использование зашифрованных коммуникаций облегчит задачу по обнаружению злоумышленников, если они уже оказались в промышленной сети.

При определении зон важно учитывать разделение обязанностей сотрудников. При этом необходимо отталкиваться от принципов «необходимо знать» и принципа наименьших привилегий. Например, сотрудник с ролью инженера АСУ ТП, должен обладать правами администратора к средствам АСУ ТП (ПЛК, АРМ, серверы), но этому сотруднику необязательно иметь доступ к средствам кибербезопасности, включая контроллер домена, сервер логов, сетевые системы обнаружения вторжений и т.д. Правило работает и в обратную сторону, сотрудник с ролью инженера/администратора ИБ должен иметь привилегированный доступ к средствами кибербезопасности, но он должен иметь ограниченный доступ к средствам АСУ ТП. Разделение ролей и обязанностей это хорошая возможность повысить общую защищенность системы, но во многих случаях такое разделение подразумевает дополнительные инвестиции в персонал и усложняет процедуры внутри организации. Решение о разделении обязанностей должно приниматься исходя из критичности объекта, организационной структуры компании и компетенций персонала. Пример возможного разделения ролей и прав доступа приведен в табл. 1. При этом один сотрудник может совмещать несколько ролей при наличии достаточных компетенций, таким образом, компания может сэкономить, но одновременно растут угрозы, связанные с возможностями этого сотрудника причинить ущерб компании.

Таблииа 1. Пример разделения ролей сотрудников и уровней доступа к зонам

\begin{tabular}{|l|l|l|}
\hline Роль & Доступ к зонам & Права \\
\hline Инженер АСУ ТП & $\begin{array}{l}\text { Зона систем управления, зона систем } \\
\text { управления производством, } \\
\text { демилитаризованная зона }\end{array}$ & $\begin{array}{l}\text { Полный доступ к компонентам } \\
\text { АСУ ТП, ограниченный доступ } \\
\text { к общесистемному ПО }\end{array}$ \\
\hline Инженер ИБ & $\begin{array}{l}\text { Зона систем кибербезопасности, } \\
\text { демилитаризованная зона }\end{array}$ & $\begin{array}{l}\text { Уровень доступа администратор } \\
\text { с ограничениями к средствам } \\
\text { кибербезопасности }\end{array}$ \\
\hline Инженер ПАЗ & $\begin{array}{l}\text { Зона систем промышленной } \\
\text { безопасности }\end{array}$ & Полный доступ к системам ПАЗ \\
Администратор & $\begin{array}{l}\text { Зона систем кибербезопасности, } \\
\text { демилитаризованная зона }\end{array}$ & $\begin{array}{l}\text { Полный доступ к средствам } \\
\text { кибербезопасности }\end{array}$ \\
\hline Оператор АСУ ТП & $\begin{array}{l}\text { Зона систем управления, зона систем } \\
\text { управления производством }\end{array}$ & $\begin{array}{l}\text { Пользовательский уровень } \\
\text { доступа }\end{array}$ \\
\hline
\end{tabular}

\section{5. Зоны систем промышленной безопасности и их интеграция с системами управления}

Как было отмечено выше, программно-технические комплексы, входящие в зону систем промышленной безопасности, являются последним барьером защиты от серьезных аварий на производстве, и интеграция этих систем с системами управления должна осуществляться максимально безопасным способом. Для многих применений лучшим вариантом будет оставить системы ПАЗ изолированными. Независимо от выбранной модели (интегрированная система или изолированная) необходимо соблюдать следующие рекомендации: 
- По возможности необходимо избегать объединения в одну сеть независимых систем ПАЗ (или приборных систем безопасности - ПСБ) отвечающих за разные технологические установки. Каждый случай объединения независимых систем ПАЗ должен рассматриваться с учетом рисков комплексной безопасности.

- Если система ПАЗ изолирована, это не означает, что ее не нужно защищать. Переносные медиа устройства, инженерные ноутбуки могут быть источником киберугроз. Сотрудники могут (в том числе из лучших побуждений) подключить $3 \mathrm{G} / 4 \mathrm{G}$ модемы или использовать персональные Wi-Fi точки для подключения этих систем к сети Интернет (например, чтобы по месту скачать обновление, документацию и т.д.). Если система ПАЗ проектируется как изолированная, должны быть предусмотрены инструменты (желательно автоматизированные), чтобы убедиться, что она остаётся изолированной в любой момент времени.

- При необходимости интеграции ПАЗ с системами управления необходимо выбирать наиболее безопасный способ интеграции, соответствующий корпоративным стандартам и требованиям регуляторов (если таковые имеются).

Существует три основных сценария интеграции ПАЗ с системами управления. Первый сценарий показан на рис. 2 и называется прямая интеграция. В этом случае локальная сеть системы ПАЗ напрямую интегрируется с сетью системы управления по Ethernet. При таком способе интеграции обязательно использование межсетевых экранов (МСЭ) на границе зон. Если использование МСЭ не предусмотрено следует избегать таких сценариев. Правила межсетевого экранирования должны быть сконфигурированы таким образом, чтобы предотвратить любые несанкционированные изменения уставок ПАЗ из системы управления, на случай если последняя была скомпрометирована. В организациях должны быть внедрены должные политики и процедуры позволяющие убедиться, что прошивки межсетевых экранов обновлены, правила настроены, как предписано проектом, и не было попыток несанкционированного изменения конфигурации МСЭ. Плюсом будет наличие у межсетевого экрана способности «понимать» протокол общения между системой ПАЗ и системой управления. В этом случае должен быть настроен функционал глубокого анализа пакетов (deep packet inspection, DPI) с целью блокирования пакетов, имеющих запрещенные команды, например, команды на запись уставок в контроллер ПАЗ.

Некоторые вендоры включают базовый функционал МСЭ в коммуникационные модули контроллеров. Со временем, когда этот функционал будет достаточно развит от использования сторонних МСЭ можно будет отказаться.

Второй сценарий показан на рис. 3 и называется интеграция через промежуточное оборудование. В соответствии с этим сценарием системы ПАЗ подключаются по Ethernet через систему контроллеры системы управления с помощь специальных коммуникационных модулей или выделенных портов.

В большинстве случаев такая архитектура является более безопасной по сравнению с прямой интеграцией, так как чтобы добраться до ПАЗ злоумышленнику нужно получить полный доступ к контроллерам системы управления. Необходимо внимательно изучить технологию работы коммуникационного модуля, в некоторых системах коммуникационные модули работают в прозрачном режиме и предоставляют прямой доступ из сети управления к нижестоящим устройствам. В таком случае использование дополнительных мер защиты (межсетевые экраны) обязательно.

Если коммуникационные модули контроллеров сети управления и/или контроллера системы ПАЗ имеют встроенный развитый функционал межсетевого экранирования, то использование сторонних межсетевых экранов не требуется. 


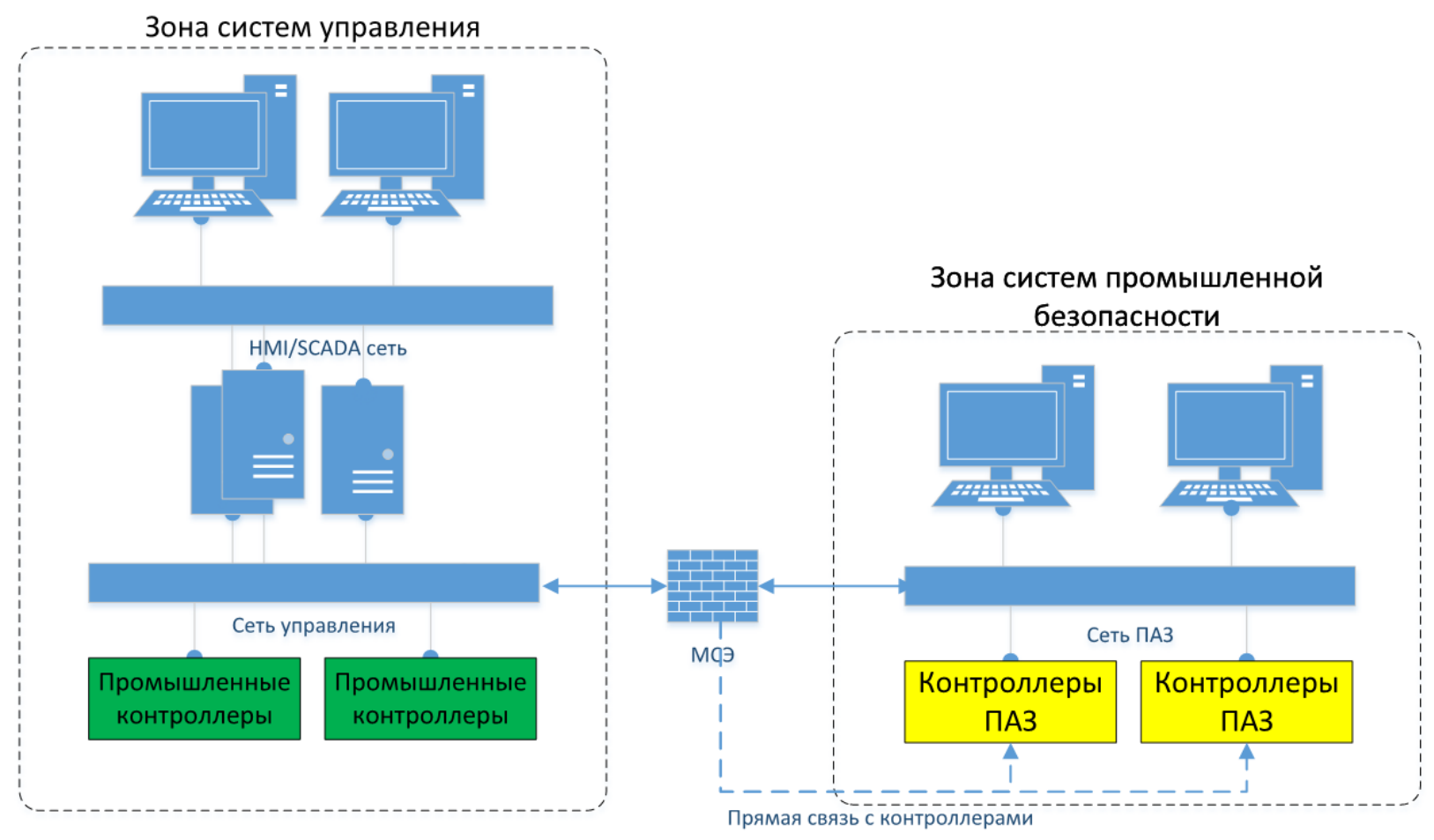

Рис. 2. Пример интеграции системы ПАЗ с системой управления. Прямая интеграчия

(Fig. 2. Example of integration of an emergency shutdown system with a control system. Direct integration)

Третий сценарий представляет собой наиболее безопасный способ интеграции по сравнению с остальными. В этом сценарии система ПАЗ интегрируется с системой управления по последовательным интерфейсам (чаще всего по RS-485). Пример такого подключения показан на рис. 4.

При использовании такого метода подключения нет необходимости в дополнительных средствах защиты, само по себе использование последовательных интерфейсов значительно снижает риск успешной атаки на систему ПАЗ даже при взломанной системе управления.

Важно отметить, что для обеспечения максимальной защиты контроллеры ПАЗ должны иметь функцию отключения записи уставок ПАЗ через последовательный интерфейс, иначе остается легальная возможность изменения уставок ПАЗ через систему управления, чем могут воспользоваться атакующие. Если все сделано корректно и на контроллере активирована данная функция, то остаются только теоретические шансы на взлом системы ПАЗ по сети. Авторам не удалось найти ни одного упоминания успешных атак, соответствующих описанному сценарию, проведенных в лабораторных или реальных условиях. 
Ян А. Сухих, Дмитрий И. Правиков, Алексей А. Кузичкин

РАЗРАБОТКА ЗАЩИЩЕННЫХ АРХИТЕКТУР АВТОМАТИЗИРОВАННЫХ СИСТЕМ УПРАВЛЕНИЯ ТЕХНОЛОГИЧЕСКИМИ ПРОЦЕССАМИ

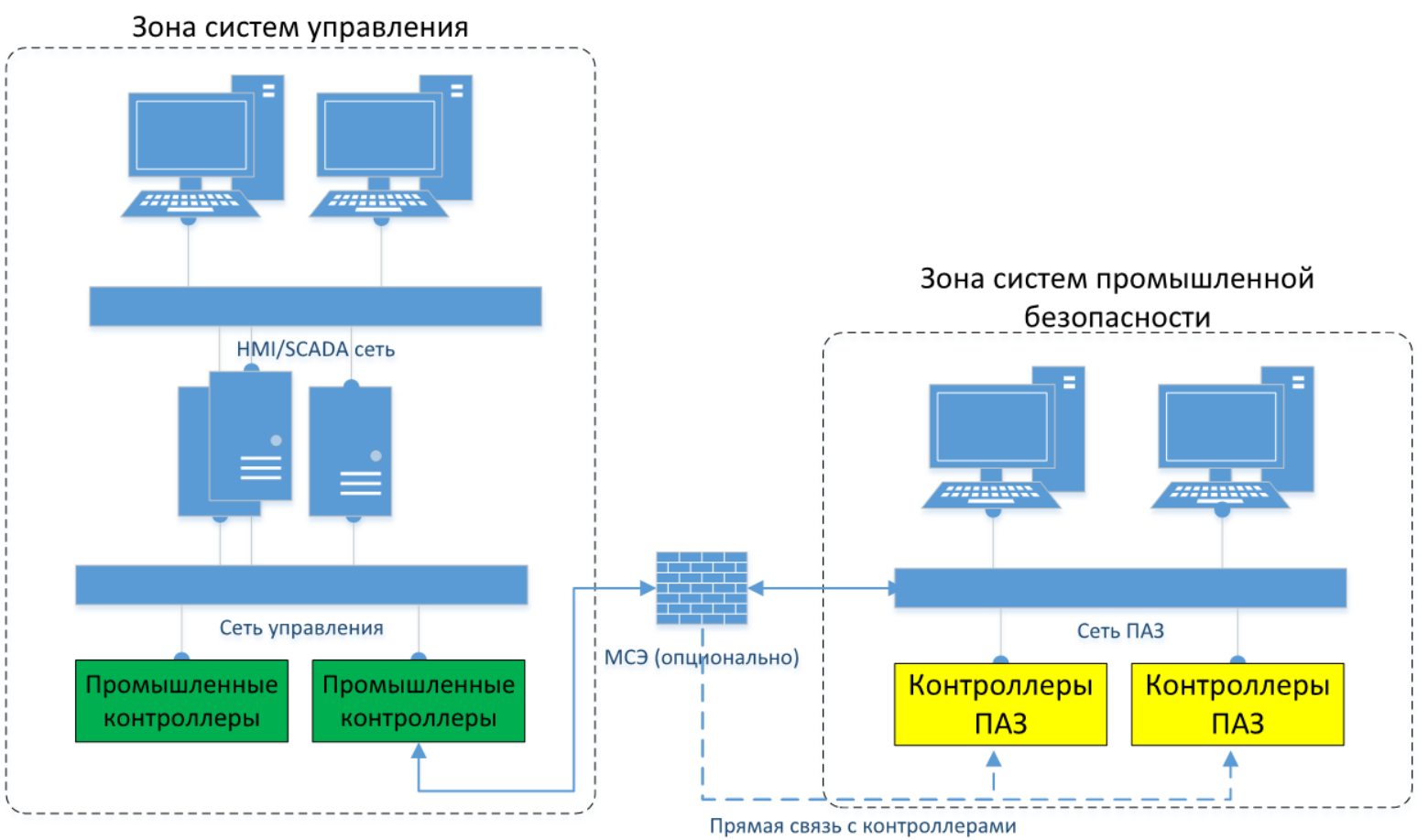

Рис. 3. Пример интеграции системы ПАЗ с системой управления.

Интеграчия через промежуточное оборудование

(Fig. 3. Example of integration of an emergency shutdown system with a control system. Indirect integration)

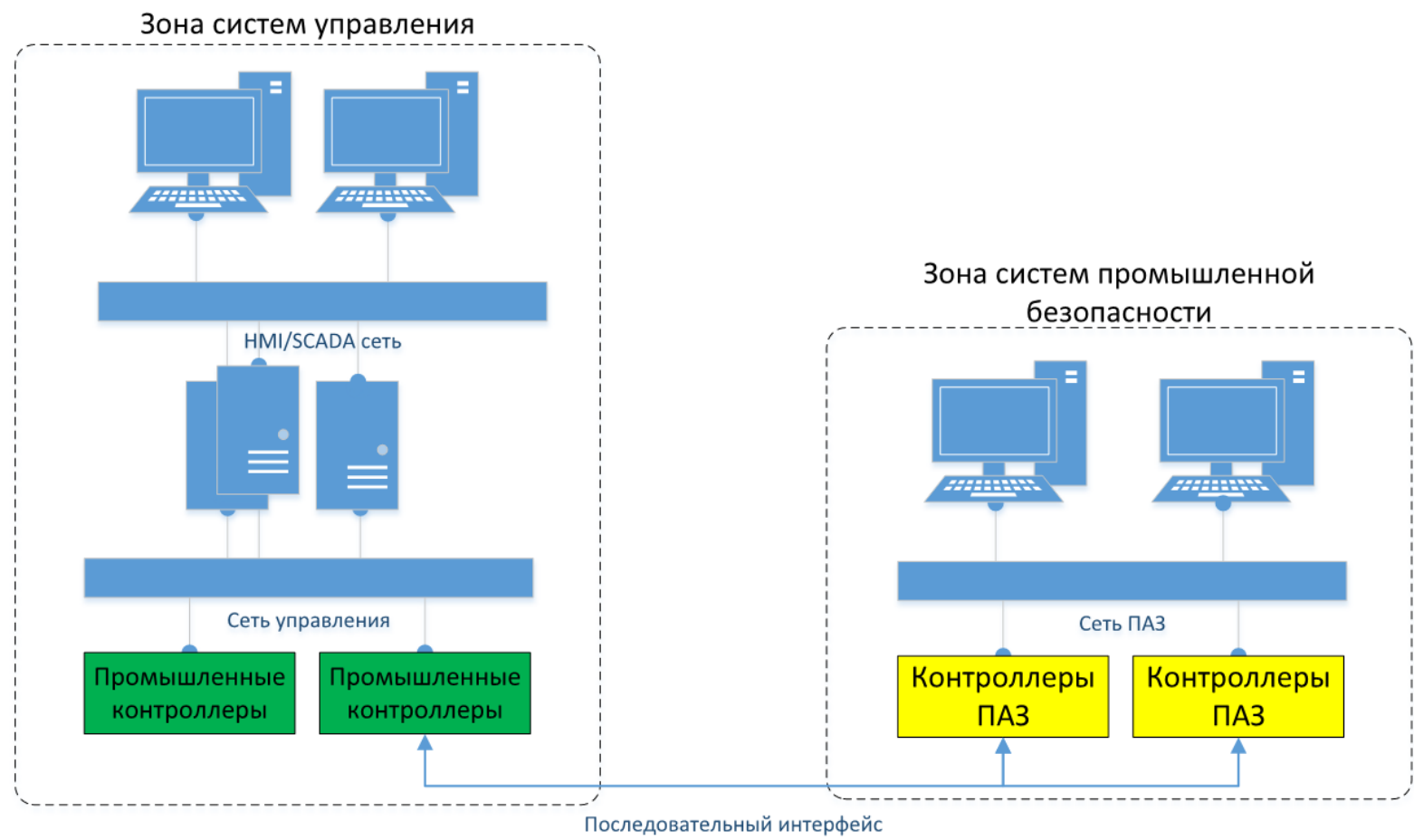

Рис. 4. Пример интеграции системы ПАЗ с системой управления.

Интеграиия по последовательному интерфейсу

(Fig. 4. Example of integration of an emergency shutdown system with a control system. Integration via serial interfaces) 
Ян А. Сухих, Дмитрий И. Правиков, Алексей А. Кузичкин

РАЗРАБОТКА ЗАЩИЩЕННЫХ АРХИТЕКТУР АВТОМАТИЗИРОВАННЫХ СИСТЕМ

УПРАВЛЕНИЯ ТЕХНОЛОГИЧЕСКИМИ ПРОЦЕССАМИ

\section{6. Приоритезация активов и средств защиты}

После разработки архитектуры защищенной промышленной системы управления необходимо расставить приоритеты по защите активов и использованию средств защиты информации. Эту процедуру, а также количественную оценку защищенности промышленных систем управления предприятиям, можно выполнить, используя оценку рисков в парадигме комплексной безопасности промышленных систем, которые не рассматриваются в данной статье.

\section{7. Внедрение мер защиты информации}

Меры по защите информации в промышленных системах управления обычно включают [14]:

- Построение ДМЗ.

- Безопасная настройка (харденинг) контроллеров и промышленного сетевого оборудования.

- Безопасная настройка рабочих станций и серверов.

- Установка и настройка систем защиты конечных узлов на рабочих станциях и серверах.

- Внедрение средств централизованного управления средствами кибербезопасности.

- Внедрение сетевых систем обнаружения вторжений (сетевые СОВ).

- Установка и настройка межсетевых экранов.

Приведем краткий обзор основных мер по защите информации в промышленных системах управления.

\section{Демилитаризованная зона}

Целью создания демилитаризованных зон является обеспечение безопасного способа коммуникации между промышленной системой управления (доверенная зона) и корпоративной сетью и другими зонами, считающимися недоверенными. Это достигается за счет того, что все коммуникации между корпоративной сетью и промышленными системами управления проходят через сервисы, размещенные в ДМЗ [15].

Если ДМЗ построена корректно, то она позволяет скрыть инфраструктуру промышленной сети управления и усложняет задачу злоумышленнику по получению доступа к критичным системам.

\section{Безопасная настройка (харденинг)}

Основной задачей безопасной настройки программных и аппаратных средств является уменьшение поверхности атаки. Это означает, что все неиспользуемые службы и сервисы, порты и протоколы, должны быть отключены, сброшены пароли по умолчанию, права и роли учетных записей пользователей настроены в соответствии с их обязанностями по принципу минимальных привилегий. Эти действия уменьшают количество векторов атак и усложняют работу атакующего.

Процесс безопасной настройки зависит от типа промышленной системы управления. Контроллеры, разработанные более 10 лет назад, практически не имеют возможностей по харденингу, в то время как современные средства автоматизации имеют достаточно широкие возможности по обеспечению информационной безопасности. В зависимости от вендора и типа оборудования это могут быть: проверка целостности прошивки, различные уровни доступа к сервисам, возможность отключения неиспользуемых служб и сервисов, белые списки и многое другое. Для повышения уровня защищенности все заложенные разработчиками возможности должны быть правильно использованы при проектировании и пуско-наладке системы автоматизации. 
Ян А. Сухих, Дмитрий И. Правиков, Алексей А. Кузичкин

Процесс безопасной настройки распространяется на все оборудование и ПО, входящие в состав промышленной системы управления: активное сетевое оборудование, рабочие станции, серверы, средства ЧМИ, сопутствующие системы и другие. При выполнении работ по безопасной настройке необходимо помнить, что доступность является максимальным приоритетом в промышленных системах управления, поэтому безопасная настройка должна выполняться в соответствии с рекомендациями производителя и/или предварительно тестироваться на стенде.

Защита рабочих станций и серверов

Решения класса защита конечных узлов для рабочих станций и серверов включает:

- Антивирусную защиту (АВ3).

- Контроль запуска приложений / белые списки.

- Контроль целостности.

- Контроль подключаемых устройств.

- Системы обнаружения вторжений для конечных узлов.

- Другие сервисы (защита от шифровальщиков, контроль Wi-Fi, Bluetooth, и т.д.).

Некоторые вендоры предлагаю эти решения в составе единого продукта, другие как отдельные сервисы. Выбор конкретных продуктов зависит от имеющихся корпоративных стандартов, рассматриваемых угроз, типа оборудования и общесистемного программного обеспечения, а также рекомендаций вендора.

\section{Централизованные средства управления ИБ}

Централизованные средства управления ИБ могут включать в себя:

- Контроллер домена. Используется для централизованного управления учётными данными и политиками Windows.

- Системы централизованного управления антивирусным ПО. Эти сервисы позволяют централизованно управлять системами класс защиты конечных узлов и обновлять базы решающих правил.

- Централизованное средство сбора и хранения логов. Обычно для этих целей используется syslog сервер, который собирает логи со всех устройств в сети.

- Сервер обновлений. Это может быть WSUS или другой сервис, позволяющий централизованно управлять обновлением операционной системы.

- Другие сервисы (сервер резервного копирования, certification authority server и др.).

В небольших системах АСУ ТП управление политиками ОС, конфигурацией систем защиты конечных узлов, учётными данными пользователей и т.д. можно выполнять вручную, что позволяет снизить капитальные затраты на создание защищенной системы.

Для средних и больших АСУ ТП настоятельно рекомендуется использование централизованных средств управления ИБ.

В приложении 1 приведены результаты опроса экспертного сообщества с целью выяснить при каком размере системы использование централизованных средств управления ИБ становится необходимым.

Сетевые системы обнаружения вторжений

Сетевые системы обнаружения вторжений (COB) используются для мониторинга трафика в сети с целью выявления вредоносных активностей. Работа сетевых $\mathrm{COB}$, как правило, основывается на двух базовых принципах:

- Определение на основе сигнатур.

- Определение на основе аномалий. 
Ян А. Сухих, Дмитрий И. Правиков, Алексей А. Кузичкин

РАЗРАБОТКА ЗАЩИЩЕННЫХ АРХИТЕКТУР АВТОМАТИЗИРОВАННЫХ СИСТЕМ УПРАВЛЕНИЯ ТЕХНОЛОГИЧЕСКИМИ ПРОЦЕССАМИ

Оба метода прекрасно дополняют друг друга. Определение вредоносной активности на основе аномалий хорошо работает при выявлении необычных (нестандартных для этой системы) сетевых взаимодействий (выявление новых устройств, использования новых протоколов или новых коммуникаций между устройствами), которые могут свидетельствовать об атаке на систему. В то же время правила, основанные на сигнатурном методе, могут выявить атаки в легитимном трафике (например, SQLинъекции, XSS атаки и другие).

Сетевые СОВ с функционалов глубокого сканирования пакетов (DPI) могут обеспечить дополнительный уровень защиты, например, выявлять критические значения параметров (уставок) переданные с APM на контроллеры системы управления, неразрешенную команду или другие события, которые могут свидетельствовать о кибератаке. Обычно предельные значения уставок/коды команд и другие триггеры, по которым срабатывают COB с DPI, устанавливают службы заказчика либо системные интеграторы на основе технологических карт промышленных установок. Этот процесс является крайне трудоемким, поэтому на рынке появились решения, которые могут самостоятельно выявлять отклонения от нормального хода технологического процесса, что существенно сокращает трудозатраты на внедрение систем. Эти системы работают на основе нейронных сетей и/или статистическом анализе данных.

Некоторые сетевые системы обнаружения вторжений могут взаимодействовать с межсетевыми экранами, чтобы «на лету» менять правила межсетевого экранирования при обнаружении атаки с целью ее предотвращения.

Сетевые СОВ важный элемент защиты промышленных систем управления. Они позволяют выявить, а в некоторых случаях и предотвратить, атаки на ранних стадиях, когда эти атаки еще не способны нанести реальный ущерб.

Межсетевые экраны

Межсетевые экраны - это базовый элемент любой архитектуры защищенной АСУ ТП. Весь трафик, который передается между зонами проходит через МСЭ. На уровне межсетевых экранов описываются правила, по которым зоны могут взаимодействовать между собой [16].

Для того что бы правила межсетевого экранирования можно было корректно настроить предварительно должны быть подробно описаны все информационные потоки между зонами. Эту информацию должен предоставить вендор и/или системный интегратор в зависимости от типа системы и того, кто ее внедрял. Как минимум, описание информационных потоков должно содержать:

- Название сервиса и его назначение.

- Протоколы и порты, IP адреса источника и назначения для каждой коммуникации.

- Описание хостов, подсетей, их назначение и адреса.

Эта информация поможет корректно сформировать правила. В дополнение к информации об информационных потоках необходимо следовать лучшим практикам по настройке межсетевых экранов, а именно:

- смена паролей по умолчанию;

- при работе следует избегать использования учетных данных администратора или root пользователя;

- всегда используйте блокирующее по умолчанию правило; 
Ян А. Сухих, Дмитрий И. Правиков, Алексей А. Кузичкин

- следует избегать использования опции «любой» в разрешающих правилах. Старайтесь использовать IP адреса конкретных устройств, в крайнем случае адреса подсетей;

- создавайте правила максимально короткими и понятными;

- всегда оставляйте комментарии к правилам и документируйте конфигурацию.

Больше информации о лучших практиках по настройке МСЭ приведено в [17].

\section{Заключение}

В статье представлено высокоуровневое описание правил построения защищенных АCУ ТП в соответствии с доступными на текущий момент национальными и международными стандартами (в частности NIST "Framework for Improving Critical infrastructure Cybersecurity", МЭК 62443, "Cyber Security for Industrial Automation and Control Systems (IACS) EDITION 2" by HSE UK, №187-Ф3 «О безопасности критической информационной инфраструктуры Российской Федерации», включая подзаконные акты), а также опытом практической реализации подобных систем. В работе описаны основные шаги (этапы) разработки архитектуры защищенной АСУ ТП и описаны основные меры по защите информации, которые наиболее востребованы на реальных объектах.

Информация, представленная в статье, аккумулирует и раскрывает требования национальных и международных стандартов. Представленная методология позволяет осознанно подойти к вопросам разработки архитектур защищенных АСУ ТП и в целом повысить защищенность как создаваемых, так и уже внедренных промышленных систем управления.

В статье рассмотрено понятие комплексной безопасности промышленных объектов. На текущий момент теоретические исследования и опыт практической реализации систем защиты показывает, что кибербезопасность промышленных систем нельзя рассматривать в отрыве от функциональной и операционной безопасности. Как следствие, только рассматривая их в комплексе можно получить объективную картину, поэтому при анализе защищенности и проведении анализа киберрисков необходимо оперировать понятием комплексной безопасности. 
Ян А. Сухих, Дмитрий И. Правиков, Алексей А. Кузичкин

РАЗРАБОТКА ЗАЩИЩЕННЫХ АРХИТЕКТУР АВТОМАТИЗИРОВАННЫХ СИСТЕМ УПРАВЛЕНИЯ ТЕХНОЛОГИЧЕСКИМИ ПРОЦЕССАМИ

Приложение 1

Результаты опроса экспертного сообщества о целесообразности использования централизованных средств управления ИБ в зависимости от размеров АСУ ТП

КАКОЙ МИНИМАЛЬНЫЙ РАЗМЕР АВТОМАТИЗИРОВАННОЙ СИСТЕМЫ (СОВОКУПНОЕ КОЛИЧЕСТВО АРМ И СЕРВЕРОВ) ВЫ СЧИТАЕТЕ ОПРАВДАННЫМ ДЛЯ ИСПОЛЬЗОВАНИЯ КОНТРОЛЛЕРА ДОМЕНА?

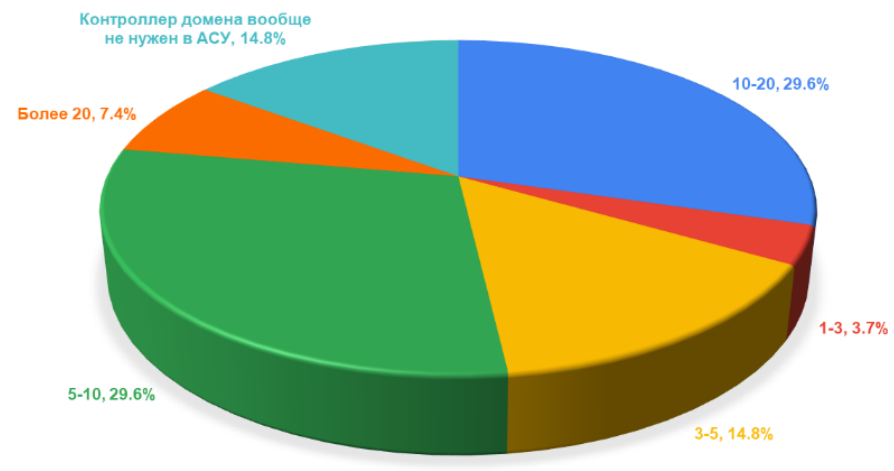

Рис. 1А. Зависимость потребности в контроллере домена от размера системь

(Fig. 1A. A dependency between a control system's size and a need for a domain controller)

Использование контроллера домена одинаковое количество опрощенных считают целесообразным для систем из 5-10 и 10-20 машин (рис. 1А). Учитывая разделение голосов в других группах и наш опыт, предлагаем считать оптимальным для использования контроллера домена системы, в которых количество АРМ и серверов, составляет от 5 до 10 машин.

КАКОЙ МИНИМАЛЬНЫЙ РАЗМЕР АВТОМАТИЗИРОВАННОЙ СИСТЕМЫ (СОВОКУПНОЕ КОЛИЧЕСТВО АРМ И СЕРВЕРОВ) ВЫ СЧИТАЕТЕ ОПРАВДАННЫМ ДПЯ ИСПОЛЬЗОВАНИЯ ЦЕНТРАЛИЗОВАННОГО УПРАВЛЕНИЯ СРЕДСТВАМИ АВЗ?

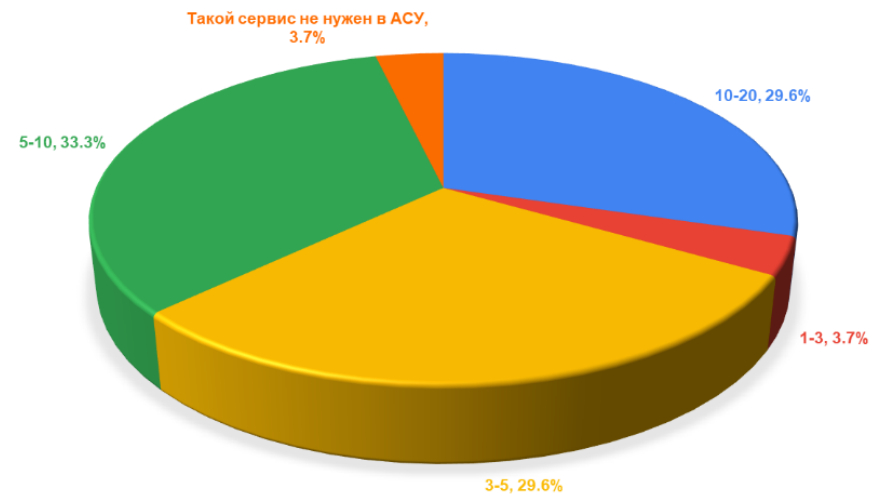

Рис. 1Б. Зависимость потребности в иеетрализованном управлении АВЗ от размера системы

(Fig. 1B. A dependency between a control system's size and a need for a centralized management of antivirus protection) 
Ян А. Сухих, Дмитрий И. Правиков, Алексей А. Кузичкин

Использование централизованного сервера для управления АВ3 большинство считает целесообразным для систем из 5-10 машин (рис. 1Б). Это же количество является медианой. Наша группа разделяет мнение сообщества.

КАКОЙ МИНИМАЛЬНЫЙ РАЗМЕР АВТОМАТИЗИРОВАННОЙ СИСТЕМЫ (СОВОКУПНОЕ КОЛИЧЕСТВО АРМ И СЕРВЕРОВ) ВЫ СЧИТАЕТЕ ОПРАВДАННЫМ ДЛЯ ИСПОЛЬЗОВАНИЯ

ВЫДЕЛЕННОГО СЕТЕВОГО ХРАНИЛИЩА ДЛЯ ХРАНЕНИЯ РЕЗЕРВНЫХ КОПИЙ?

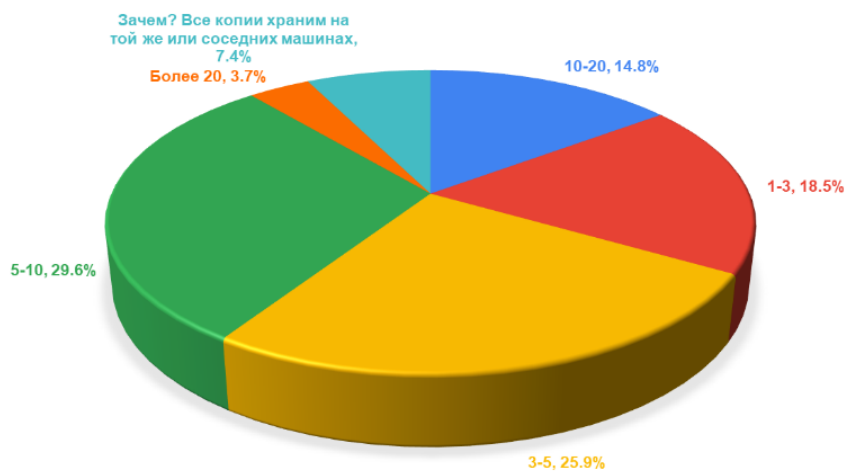

Рис. 1В. Зависимость потребности в выделенном сервере хранения резервных копий от размера системы

(Fig. $1 \mathrm{~V}$. A dependency between a control system's size and a need for a dedicated backup storage server)

Использование выделенного сетевого хранилища для резервных копий большинство проголосовавших считает оптимальным для систем из 3-5 и 5-10 машин, при этом большая группа экспертов отдала голоса за 1-3 и 10-20 машин (рис. 1В). Следовательно, использование выделенного хранилища будет целесообразно для систем из 1-5 машин в зависимости от принятых процессов и условий эксплуатации. Медианой и оптимальным выбором для большинства компаний станет использование выделенных сетевых хранилищ для систем из 3-5 машин.

КАКОЙ МИНИМАЛЬНЫЙ РАЗМЕР АВТОМАТИЗИРОВАННОЙ СИСТЕМЫ (СОВОКУПНОЕ КОЛИЧЕСТВО АРМ И СЕРВЕРОВ) ВЫ СЧИТАЕТЕ ОПРАВДАННЫМ ДЛЯ ИСПОЛЬЗОВАНИЯ ИСПОЛЬЗОВАНИЯ ЦЕНТРАЛИЗОВАННОГО УПРАВЛЕНИЯ СРЕДСТВАМИ РЕЗЕРВНОГО

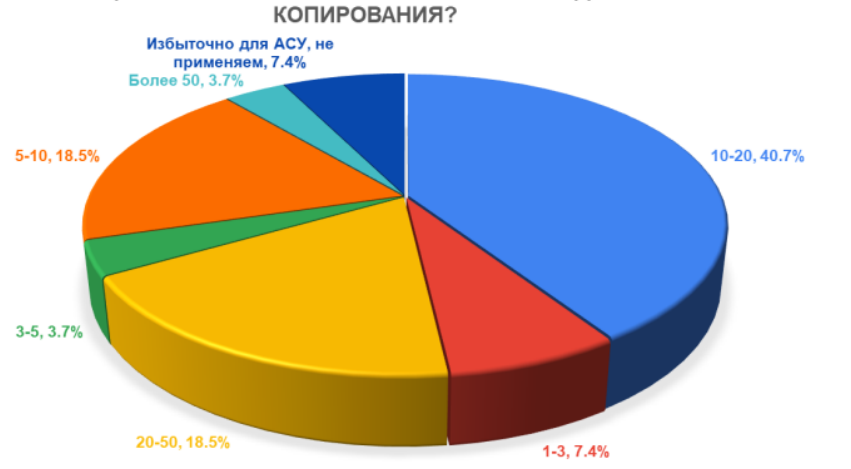

Рис. 1Г. Зависимость потребности в цуентрализованном управлении средствами резервного копирования от размера системы

(Fig. 1G. A dependency between a control system's size and a need for a centralized backup management system) 
Необходимость использования централизованного управления средствами резервного копирования большинство проголосовавших признали для систем из 10-20 машин, это же количество является медианой.

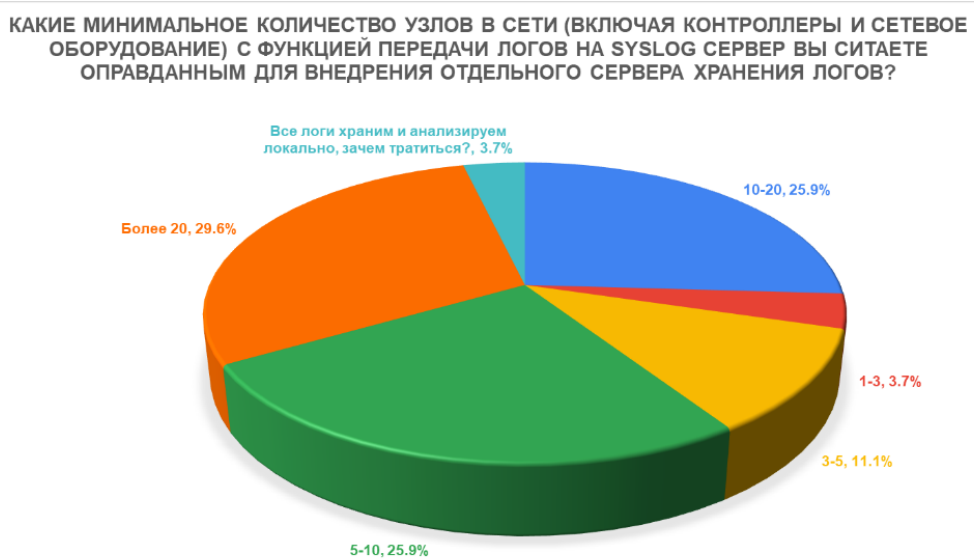

Рис. 1Д. Зависимость потребности в иентрализованном сервере хранения и обработки логов от размера системы

(Fig. 1D. A dependency between a control system's size and a need for a centralized server for storing and processing logs)

Экспертное сообщество разделилось во мнениях по поводу размера систем, для которых следует использовать выделенный сервер Syslog. Медианой являются системы из 10-20 узлов (под узлами подразумеваются не только АРМ и сервера, но и контроллеры, и сетевое оборудование). Наше мнение совпадает с оговоркой, что при использовании Open Source syslog сервера совместно с OC Linux на виртуальных машинах, использование такого решения экономически целесообразно и для небольших систем из 5-10 узлов.

\section{СПИСОК ЛИТЕРАТУРЫ:}

1. Банников Е.В. Использование ПЛК в промышленности. // International scientific review. 2019. URL: https://cyberleninka.ru/article/n/ispolzovanie-plk-v-promyshlennosti (дата обращения: 01.04.2020).

2. Андреев Ю. С., Дергачев А. М., Жаров Ф. А., Садырин Д. С. Информационная безопасность автоматизированных систем управления технологическими процессами. // Известия высших учебных заведений. Приборостроение. 2019. Т. 62, № $4 . \quad$ С. 331-336. URL: https://cyberleninka.ru/article/n/informatsionnaya-bezo-pasnost-avtomatizirovannyh-sistem-upravleniyatehnologicheskimi-protsessami (дата обращения: 01.04.2020).

3. Васильев В.И., Кириллова А.Д., Кухарев С.Н. Кибербезопасность автоматизированных систем управления промышленных объектов (современное состояние, тенденции). // Вестник УрФО. Безопасность в информационной сфере. 2018. № 4(30). С. 66-74. URL: http://www.infosecur.ru/is_30/is418_66-74.pdf (дата обращения: 01.04.2020).

4. National Institute of Standards and Technology "Framework for Improving Critical Infrastructure Cybersecurity" Version 1.1 April 16, 2018. URL: https://www.nist.gov/publications/framework-improvingcritical-infrastructure-cybersecurity-version-11 (дата обращения: 01.04.2020).

5. Серия стандартов IEC 62443. URL: https://www.isa.org/ (дата обращения: 01.04.2020).

6. Гордейчик С.В. Миссиоцентрический подход к кибербезопасности АСУ ТП. // Вопросы кибербезопасности. 2015. № 2 (10). С. 56-59. URL: https://cyberleninka.ru/article/n/missiotsentricheskiypodhod-k-kiberbezopasnosti-asu-tp (дата обращения: 01.04.2020). 
7. Yuri Bobbert, Anderson Domingues Pereira da Silva. Cybersecurity Readiness: An Empirical Study of Effective Cybersecurity Practices for Industrial Control Systems. Sci J Research \& Rev. 2(3): 2019. SJRR.MS.ID.000536. DOI: https://doi.org/10.33552/SJRR.2019.02.000536.

8. Слинин А.В. Моделирование АСУ ТП объекта нефтедобычи в контексте управления рисками ИБ. // $\begin{array}{lllllll}\text { Молодежный Вестник УГАТУ. 2019. № } 1 & \text { (20). C. 170-173. }\end{array}$ URL: https://www.elibrary.ru/item.asp?id=41122584 (дата обращения: 01.04.2020).

9. Пакулин М.А. Концепция сетевой безопасности в автоматизированных системах управления технологическим процессом (АСУ ТП) // Сборник трудов X международной научно-практической конференции молодых ученых «Программная инженерия и компьютерная техника (Майоровские чтения)». 2019. C. 103-105. URL: http://micsecs.org/media/MICSECS_RUS_2018.pdf\#page=104 (дата обращения: 01.04.2020).

10. Промыслов В.Г., Семенков К.В., Шумов А.С. Синтез архитектуры кибербезопасности для систем управления атомных электростанций. // Пробл. управл., 2019. № 3. С. 61-71 URL: http://www.mathnet.ru/php/archive.phtml?wshow=paper\&jrnid=pu\&paperid=1139\&option_lang=rus (дата обращения: 01.04.2020).

11. HSE UK, "Cyber Security for Industrial Automation and Control Systems (IACS)" EDITION 2, URL:https://www.hse.gov.uk/foi/internalops/og/og-0086.pdf (дата обращения: 01.04.2020).

12. National Security Agency, "A Framework for Assessing and Improving the Security Posture of Industrial Control Systems (ICS)", Version 1.1, Systems and network Analysis Center, National Security Agency, August 20, 2010, URL: https://apps.nsa.gov/iaarchive/library/ia-guidance/security-configuration/industrialcontrol-systems/a-framework-for-assessing-and-improving-the-security-posture.cfm (дата обращения: 01.04.2020).

13. Recommended Practice: Improving Industrial Control System Cybersecurity with Defense-in-Depth Strategies, Industrial Control Systems Cyber Emergency Response Team, September 2016,

URL: https://www.us-cert.gov/sites/default/files/recommended_practices/NCCIC_ICS-CERT_Defense_ in_Depth_2016_S508C.pdf (дата обращения: 01.04.2020).

14. Charles Kim, Electrical Engineering and Computer Science Howard University, "Cyber-Defensive Architecture for Networked Industrial Control Systems".

URL:https://www.researchgate.net/publication/312590499_CyberDefensive_Architecture_for_Networked_Ind ustrial_Control_Systems (дата обращения: 01.04.2020).

15. RE Mahan, JR Burnette, JD Fluckiger, CA Goranson, SL Clements, H Kirkham, C Tews, Pacific Northwest National Laboratory, "Secure Data Transfer Guidance for Industrial Control and SCADA Systems", September 201. DOI: https://doi.org/10.2172/1030885.

16. British Columbia Institute of Technology (BCIT), "Good Practice Guide on Firewall Deployment for SCADA and Process Control Networks (Prepared for National Infrastructure Security Coordination Centre)", National Infrastructure Security Co-ordination Centre (NISCC), February 2005, URL:https://www.energy.gov/sites/prod/files/Good\%20Practices\%20Guide\%20for\%20Firewall\%20Deployme nt.pdf (дата обращения: 01.04.2020).

17. Firewall Best Practices by Kevin Beaver, CISSP.

URL: https://www.principlelogic.com/docs/Firewall_Best_Practices.pdf (дата обращения: 01.04.2020).

\section{REFERENCES:}

[1] Bannikov E.V. Ispolsovanie programmiruemyh logicheskih kontrollerov v promishlennosty. International scientific review. 2019. URL: https://cyberleninka.ru/article/n/ispolzovanie-plk-v-promyshlennosti (accessed: 01.04.2020).

[2] Andreev U.S., Dergachev A.M., Zharov F.A., Sadyrin D.S. Informacionnaya bezopasnost avtomatizirovannyh system upravleniya tehnologicheslimy processamy. Izvestiya vyshikh uchebnyh zavediniy. Priborostroenie. 2019. Vol. 62, № 4. P. 331-336. URL: https://cyberleninka.ru/article/n/informatsionnaya-bezo-pasnostavtomatizirovannyh-sistem-upravleniya-tehnologicheskimi-protsessam (accessed: 01.04.2020) (in Russian).

[3] Vasilyev V.I., Kirillova A.D., Kuharev S.N. Kiberbezopasnost avtomatizirovannyh system upravleniya promyshlennih obiektov (sovremennoe sostoyanie, tendencii). Vestnik UrFO. Bezopasnost v informacionnoy sfere. 2018. № 4(30). P. 66-74. URL: http://www.info-secur.ru/is_30/is418_66-74.pdf (accessed: 01.04.2020) (in Russian).

[4] National Institute of Standards and Technology "Framework for Improving Critical Infrastructure Cybersecurity" Version 1.1 April 16, 2018. URL: https://www.nist.gov/publications/framework-improvingcritical-infrastructure-cybersecurity-version-11 (accessed: 01.04.2020). 
[5] IEC 62443. URL: https://www.isa.org/ (accessed: 01.04.2020).

[6] Gordeychuk S.V. Mission-centric approach to ICS/SCADA. Cybersecurity in terms of industrial. Voprosy kiberbezopasnosty. 2015. № 2 (10). P. 56-59. URL: https://cyberleninka.ru/article/n/missiotsentricheskiypodhod-k-kiberbezopasnosti-asu-tp (accessed: 01.04.2020).

[7] Yuri Bobbert, Anderson Domingues Pereira da Silva. Cybersecurity Readiness: An Empirical Study of Effective Cybersecurity Practices for Industrial Control Systems. Sci J Research \& Rev. 2(3): 2019. SJRR.MS.ID.000536. DOI: https://doi.org/10.33552/SJRR.2019.02.000536.

[8] Slinin A.V. Modelirovanie ICS/SCADA obiekta neftedobichy v kontekste upravlenia riskamy informacionnoy bezopasnosty. Molodezniy Vestnik UGATU. 2019. № 1 (20). P. $170-173$. URL: https://www.elibrary.ru/item.asp?id=41122584 (accessed: 01.04.2020) (in Russian).

[9] Pakulin M.A. Koncepcia setevoy bezopasnosty v avtomatizirovannyh systemah upravlenia tehnologicheskym processom (ICS/SCADA). Sbornik trudov X mezdunarodnoy nauchno-prakticheskoy konferencii molodyh uchenyh "Programmnaya inzeneria i komputernaya tehnika (Mayorovskie chtenia)". 2019. P. 103-105. URL: http://micsecs.org/media/MICSECS_RUS_2018.pdf\#page=104 (accessed: 01.04.2020) (in Russian).

[10] Promyslov V.G., Semenkov K.V., Shumov A.S. Sintez arhitectury kiberbezopasnosty dlya system upravlenia atomnyh electrostancii. Probl. Upravl., 2019. № 3. P. 61-71. DOI: http://doi.org/10.25728/pu.2019.3.7. URL: http://mi.mathnet.ru/pu1139 (accessed: 01.04.2020) (in Russian).

[11] HSE UK, "Cyber Security for Industrial Automation and Control Systems (IACS)" EDITION 2, URL:https://www.hse.gov.uk/foi/internalops/og/og-0086.pdf (accessed: 01.04.2020).

[12] National Security Agency, "A Framework for Assessing and Improving the Security Posture of Industrial Control Systems (ICS)", Version 1.1, Systems and network Analysis Center, National Security Agency, August 20, 2010, URL: https://apps.nsa.gov/iaarchive/library/ia-guidance/security-configuration/industrialcontrol-systems/a-framework-for-assessing-and-improving-the-security-posture.cfm (accessed: 01.04.2020).

[13] Recommended Practice: Improving Industrial Control System Cybersecurity with Defense-in-Depth Strategies, Industrial Control Systems Cyber Emergency Response Team, September 2016. URL: https://www.us-cert.gov/sites/default/files/recommended_practices/NCCIC_ICS-CERT_Defense_ in_Depth_2016_S508C.pdf (accessed: 01.04.2020).

[14] Charles Kim, Electrical Engineering and Computer Science Howard University, "Cyber-Defensive Architecture for Networked Industrial Control Systems" URL:https://www.researchgate.net/publication/312590499_CyberDefensive_Architecture_for_Networked_Ind ustrial_Control_Systems (accessed: 01.04.2020).

[15] RE Mahan, JR Burnette, JD Fluckiger, CA Goranson, SL Clements, H Kirkham, C Tews, Pacific Northwest National Laboratory, "Secure Data Transfer Guidance for Industrial Control and SCADA Systems", September 201. DOI: https://doi.org/10.2172/1030885.

[16] British Columbia Institute of Technology (BCIT), "Good Practice Guide on Firewall Deployment for SCADA and Process Control Networks (Prepared for National Infrastructure Security Coordination Centre)", National Infrastructure Security Co-ordination Centre (NISCC), February 2005, URL:https://www.energy.gov/sites/prod/files/Good\%20Practices\%20Guide\%20for\%20Firewall\%20Deployme nt.pdf (accessed: 01.04.2020).

[17] Firewall Best Practices by Kevin Beaver, CISSP.

URL: https://www.principlelogic.com/docs/Firewall_Best_Practices.pdf (accessed: 01.04.2020).

Поступила в редакциию - 11 апреля 2020 г. Окончательный вариант - 25 мая 2020 г. Received-April 11, 2020. The final version-May 25, 2020. 